\title{
Analysis of Competency Model in Enterprise Human Resource Management
}

\author{
Chengye Zhang \\ Qingdao Hotel Management College, Qingdao, 266100, China
}

Keywords: Enterprise. Human resource management. Competency model. Competency feature. Solution

\begin{abstract}
In modern enterprise human resource management, competency model is a key point in management research. Competency model effectively makes up for traditional human resource management in the thought and method of human resource management. Application of competency model in modern enterprise human resource management will contribute to breaking through shackles of traditional human resource management, advancing with the times and meeting the requirements of times for enterprise human resource management. To further improve efficiency of enterprise human resource management, the study on competency model will also be improved. This paper will analyze the application and current development problems on the basis of briefly introducing competency model and then put forward measures to solve problems.
\end{abstract}

\section{Introduction}

As economy develops continuously, under new economic rimes, enterprise human resource management is faced with any social changes. Under new historical background, traditional human resource management mode cannot satisfy enterprise needs. Meanwhile, as China's socialist market economy system establishes and develops, under fierce competitions, modern enterprise competitions is increasingly partial to personnel competition. So, to adapt such competition, enterprise human resource management must be reformed. In particular, in fierce market competition, improving personnel competency of enterprise human resources is an important problem many enterprises urgently need to solve. In order to promote Chinese enterprises remaining invincible in competitions, this paper briefly analyzes competency model in enterprise human resource management and proposes several solutions.

\section{Overview of competency model in enterprise human resource management}

In 1970s, when American scholars studied human resource management, they put forward competency according to related features of human resource management. Competency is a deeper-level standard to effectively distinguish the personnel with excellent performance and the personnel with general performance. In practical work, to judge whether personnel can bear more work on the basis of perfectly completing tasks, many enterprises adopt competency model for judgment. Competency judgment requires comprehensive evaluation of personnel so as to judge the indexes required by high-quality performance. In enterprise human resource management, competency is generally divided into surface competency and core competency. For surface competency, individual skills and knowledge are the core indexes. Meanwhile, these surface competencies are hard indexes which can be easily gained through learning and training. Personnel can meet work requirements through learning and training for some time. But, core competency with invisible features such as value and self-concept cannot improve through short-term training and learning. Besides, core competency cannot be accurately estimated. Core competency indexes are relatively subjective. Human values and motivations only exist in people's hearts and alter with the changes in living environment and individual subject feeling. But meanwhile, in work, people's core competency owns high stability and cannot change within certain period. So, in specific evaluation process, core competency can effectively and accurately evaluate individual work performance. 


\section{Application of competency model in enterprise human resource management}

As society and economy continuously develop, enterprise human resource management must change traditional human resource management model in order to satisfy social and economic demands with rapid development. Competency model provides a new management mode for enterprise human resource management. As everyone knows, under the economic background with rapid changes and development, dynamic human resource management must be realized in order to improve human resource management effeminacy. At the same time, application of competency model in enterprise human resource management can effectively judge whether personnel are able to take charge of current posts. Adjustment and optimization of competency model can effectively optimize human resource allocation and makes enterprises use human resource more rationally and scientifically.

\section{Competency model in recruitment}

In human resource management, personnel recruitment and appointment are the primary work. In traditional human resource management, personnel recruitment and appointment only pay attention to people's surface competency such as skills and knowledge. Overvaluing external skills and knowledge will generally ignore personnel's inherent potential, which will bring loss to enterprises to some extent. To solve this problem, it is especially important to apply competency model in personnel recruitment. Competency model can be used to evaluate and judge external and internal competency of applicants and overall know whether applicants comply with enterprise culture and bring benefits to enterprise development. This requires enterprises human resource management department correctly cognizing and using competency model. During application of competency recruitment system, it is required to implement personnel recruitment strategy from two aspects: post competency and competency management intention.

\section{Competency model in personnel training and development}

In human resource management, personnel training and development are one of the key points. But, in a bid to improve scientificity and pertinence of training and development, competency model must be applied in personnel training and development. Application of competency model can accurately master post demand so as to conduct targeted training of human resources. When competency model in enterprise human resource management evaluates post demand, corresponding exclusive post competency model will be set up. Based on this model, related training course system will be developed according to demands and finally provided for post personnel so as to make personnel adapt post requirements after receiving training and improve pertinence and scientization of post training.

\section{Competency model in performance management}

In traditional human resource management, performance management is also one of key contents. But traditional performance management stresses personnel performance appraisal and lacks comprehensive evaluation of personnel's knowledge and professional skills. After competency model is applied in human resource management, corresponding performance management systems can be established. Through scientific planning and demonstration, systematic performance management system can not just really reflect personnel's comprehensive performance, but also promote personnel's enthusiasm through scientific incentive mechanism. Optimization of performance management can fundamentally ensure permanent improvement of enterprise performance.

\section{Problems of competency model in enterprise human resource management}

In order to satisfy enterprise demand for human resource management, both foreign enterprises and Chinese enterprises start to enhance researches of competency model. At present, competency model is an effective measure to make up for traditional human resource management and can effectively solve the problems traditional human resource management cannot solve. Meanwhile, it is also one of important measures to boost enterprise market competitions. In foreign countries, many 
enterprises apply competency model in human resource management. But in China, competency model is still in the state of theoretical research. Some enterprises start to introduce competency model technically. But due to various reasons, there exist some problems during application and generalization of competency model.

\section{Chinese enterprises do not pay much attention to human resource management}

Seeing from enterprise development level, for the success of Chinese enterprises, most enterprises benefit from successful operation of opportunity resources. Many successful enterprises lack explicit core competitiveness, mature enterprise knowledge cultural environment of enterprise. Successful enterprises in such situation often neglect internal management enhancement in future development. Naturally, they cannot see the important significance of human resource management on enterprise development. The application of competency model needs a mature human resource management environment to make sure the framework system and management method can normally work. The lack of good human resource management results in great barriers for generalizing competency model in Chinese enterprises. On the other hand, correct application of competency model is based on rational human resource management. If there is lack of perfect human resource management, competency model cannot normally work. Meanwhile, due to the lack of correct cognition of human resource management, there is lack of correct grasp of the thought and idea of competency model. This also imposes certain influences on development and generalization of competency model in Chinese enterprises. In China, although the reform and opening-up policy has been implemented for decades, so far, some enterprises do not realize marketization in personnel recruitment. Human resource management system is still not perfect. Especially for state-owned enterprises, large problems exist in human resource management. It needs time to solve these problems. Therefore, generalization and application of competency model also needs a long-term development process.

\section{Low localization degree of competency model}

It is known from the above analysis that most enterprises in China introduce competency model from foreign countries. Since the introduction time is short, localization degree of the model is still low. When some enterprises introduce competency model, they fail to combine Chinese national conditions, social and economic conditions. When applying competency model, they do not adjust competency model according to their features. Meanwhile, due to the lack of the evaluation system matched with the competency model, the application effect of competency model is greatly influenced. Construction of competency model is a long-term and huge project. The application effect of the model is vital. The imperfect evaluation system reflecting the application effect causes the application effect of the model cannot be reflected, thus influencing the application and generalization. The cost for introducing competency model from foreign countries is high. In addition, application of competency model in human resource management also has certain risks. The development of competency model also lacks certain necessity. Many objective factors influence and restrict generalization and development of competency model to some extent.

\section{Solutions of competency model in enterprise human resource management}

To further boost enterprise human resource management efficiency, the following must be adopted to solve the problems during application of competency model.

\section{To perfect appraisal mechanism of competency model in human resource management}

As economy develops, the society changes quickly, too. Enterprises under rapid changes continuously accelerate their development. Many irresistible factors make enterprises difficult to formulate the appraisal mechanism satisfying all. For the employees with high autonomy, it is hard to realize real-time supervision of the work process. The work effects of such employees have no explicit definition standards, so there are problems for performance appraisal of human resource management. Thus, based on application of competency model, it is required to reconstruct reasonable appraisal mechanism. For example, for the employees difficult to evaluate them through work results, it is required to mainly evaluate their working ability and attitude so as to further perfect appraisal mechanism of human resource management. 


\section{To perfect salary mechanism of competency model in human resource management}

Under the requirements of modern society, single individual ability is weakened, while the functions of teams or groups are further magnified. Under the reality of aggravated market competitions, basic unit of enterprises organizational structure is not individual any longer, but working group or team. In many modern enterprises, the same job is not completely singly by one person. Besides, work description changes into provisions of work task and nature from narration of previous post task and responsibility. Such transformation makes the same team have no clear right and duty division when doing the same work. All members in the team or group will be responsible for the team performance. On this basis, enterprise salary mechanism also changes correspondingly. The post will not decide the salary any longer in traditional human resource management. In competency model, the salary is based on individual ability. Under new salary mechanism, broadband salary system is formulated according to individual ability. Broadband salary system can effectively promote comprehensive development of employees' ability and adapt more work in an enterprise. Development prospect of individual professional career is brighter. Besides, the development ways become more. Broadband salary system further enriches employees' job contents and brings convenience for enterprises to rationally arrange work. Through perfecting salary mechanism of human resource management, enterprises can also reasonably reduce personnel on the basis of comprehensive development of personnel, improve their use potential and further reduce enterprise human cost.

\section{Conclusions}

To sum up, application of competency model in human resource management supplements traditional human resource management. To further decrease cost in market competitions, boost enterprise efficiency and realize great improvement of economic efficiency, Chinese enterprises must attach importance to human resource management inwardly and scientifically apply competency model in human resource management. Through reforming human resource management system in a scientific way, enterprises can retain personnel and attract more personnel. Although competency model is still not mature in China and in the research stage, as market economy develops and China's economic system is further reformed, competency model will be further mature and develop in China. As well, it will be widely applied to promote further development of Chinese enterprises.

\section{References}

[1] Deng Zuoming: Application of competency model in human resource management of private enterprises, Enterprise Economy, 2011(06)

[2] Li Li, Hu Bei: Study on integration of competency model and human resource, Studies in Dialectics of Nature, 2008(09)

[3] Huang Guidong: Study on engineering investigation and design of enterprise human resource management based on competency model, Science and Technology of West China, 2010(07)

[4] Rao Huixia, Wu Haiyan: Review of foreign research progress on competency, Science and Technology Management Research, 2010(16)

[5] Wang Zhongcheng: Innovation of human resource management of state-owned enterprises based on competency model, Science and Technology Management Research, 2010(13) 